\title{
Electrochemical properties of alkali bis(trifluoromethylsulfonyl)amides and their eutectic mixtures
}

\section{$\operatorname{AUTHOR}(S)$ :}

Kubota, Keigo; Tamaki, Kenichiro; Nohira, Toshiyuki; Goto, Takuya; Hagiwara, Rika

\section{CITATION:}

Kubota, Keigo ...[et al]. Electrochemical properties of alkali

bis(trifluoromethylsulfonyl)amides and their eutectic mixtures. Electrochimica Acta 2010, 55(3): 1113-1119

\section{ISSUE DATE:}

2010-01-01

URL:

http://hdl.handle.net/2433/89693

\section{RIGHT:}

c 2009 Elsevier Ltd. All rights reserved.; この論文は出版社版でありませ ん。引用の際には出版社版をご確認ご利用ください。; This is not the published version. Please cite only the published version. 


\section{Electrochemical properties of alkali bis(trifluoromethylsulfonyl)amides and their eutectic mixtures}

Keigo Kubota, Kenichiro Tamaki, Toshiyuki Nohira, Takuya Goto, Rika Hagiwara*

Graduate School of Energy Science, Kyoto University

Sakyo-ku, Kyoto 606-8501, Japan

hagiwara@energy.kyoto-u.ac.jp

Keywords: Bis(trifluoromethylsulfonyl)amide; Molten salt; Ionic conductivity; Viscosity;

Electrochemical window

Densities, viscosities and ionic conductivities of single salts and the binary eutectic mixtures of alkali bis(trifluoromethylsulfonyl)amides, MTFSAs ( $\mathrm{M}=\mathrm{Li}, \mathrm{Na}, \mathrm{K}, \mathrm{Rb}$, Cs), were measured in the temperature range of 413-573 K. Cyclic voltammetry revealed that the binary eutectic melts have wide electrochemical windows of 5.0-6.0 V. It was found that alkali metals reversibly deposit on a nickel electrode at the cathode limit potentials. The order of the deposition potential was determined to be $\mathrm{Na}>\mathrm{Li}>(\mathrm{K}, \mathrm{Rb}, \mathrm{Cs})$. 


\section{Introduction}

We have recently reported binary and ternary phase diagrams for MTFSAs $(\mathrm{M}=\mathrm{Li}, \mathrm{Na}, \mathrm{K}$,

$\mathrm{Rb}, \mathrm{Cs})[1,2]$. Table 1 shows the eutectic compositions and temperatures of binary MTFSA salt mixtures [1]. Although the melting points of single MTFSA salts are relatively high (typically above $400 \mathrm{~K}$ ), it is possible to obtain mixtures possessing melting points in the intermediate temperature range (373 to 473$) \mathrm{K}[1,2]$. Among the ternary systems, we have already reported that the LiTFSA-KTFSA-CsTFSA system is highly promising as an electrolyte for rechargeable lithium metal battery owing to its high conductivity, $14.2 \mathrm{mS} \mathrm{cm}^{-1}$, wide electrochemical window, $5.0 \mathrm{~V}$ with a cathode limit of lithium metal deposition with a good cycle performance at $423 \mathrm{~K}$ [3].

In this study, we examined physicochemical properties (densities, viscosities, ionic conductivities) and electrochemical properties of single salt melts and the binary eutectic melts for MTFSAs and discussed on the effect of mixing on the physicochemical properties of MTFSAs. 


\section{Experimental}

Reagents and synthetic procedures are basically the same as reported in the previous study

[2]. Several important points and new procedures are described here. LiTFSA (Morita Chemical Industries, purity $>99.0 \%$ ) is purchased and dried under vacuum before measurement. HTFSA (Morita Chemical Industries, purity $>99.0 \%$ ) and $\mathrm{M}_{2} \mathrm{CO}_{3}(\mathrm{M}=\mathrm{Na}, \mathrm{K}, \mathrm{Rb}$, Cs) were starting chemicals. MTFSAs except for LiTFSA were synthesized by the reaction between HTFSA and $\mathrm{M}_{2} \mathrm{CO}_{3}$.

Densities, viscosities and ionic conductivities were measured from the temperatures higher than the melting points by about $20 \mathrm{~K}$ up to around $573 \mathrm{~K}$. Densities were measured by Archimedean method. Viscosities were measured by a viscometer (DV-II+ PRO, Brookfield Engineering Laboratories). Ionic conductivities were measured with an AC impedance method (IVIUMSTAT, Ivium technologies, frequency: $1 \mathrm{MHz}$ ). The cell constant was determined by the measurement of a $\mathrm{KCl}$ standard solution at $291 \mathrm{~K}$.

Electrochemical windows of the eutectic LiTFSA-MTFSA $(\mathrm{M}=\mathrm{Na}, \mathrm{K}, \mathrm{Rb}, \mathrm{Cs})$, and NaTFSA-CsTFSA melts were measured by means of cyclic voltammetry. The limiting potentials are defined as the potentials at a current density of $0.1 \mathrm{~mA} \mathrm{~cm}{ }^{-2}$. Electrochemical measurements were performed by the three-electrode method in an argon-filled glove box. A nickel disk (6 mm in diameter, $0.1 \mathrm{~mm}$ in thickness) or a glassy carbon rod (3 $\mathrm{mm}$ in diameter) was used for the working electrode. A glassy carbon rod (3 mm in diameter) was also used for the counter electrode. A lithium 
foil was used for the reference electrode in the eutectic LiTFSA-MTFSA (M = K, Rb, Cs) melts. In the cases of Li67-Na33 (the abbreviation of the eutectic LiTFSA-NaTFSA with $x_{\text {LiTFSA }}=0.33$. All the binary salts described here are eutectic mixtures.) and Na07-Cs93 melts, sodium metal was used for the reference electrode material. The scan rate for the cyclic voltammetry was $10 \mathrm{mV} \mathrm{s}^{-1}$. Galvanostatic electrolysis was performed to obtain the deposit for the identification of the reactions at the cathode limits. The deposited substances on a nickel electrode after the electrolysis were analyzed by means of differential scanning calorimetry (DSC) and X-ray diffraction (XRD) analysis. 


\section{Results and discussion}

3.1 Viscosities of single salts and binary eutectic mixtures

Figure 1 shows Arrhenius plots of viscosities for (a) single salts, (b) eutectic

LiTFSA-MTFSA (M = Na, K, Rb, Cs) and (c) the eutectic NaTFSA-MTFSA $(M=K, R b, C s)$.

Distinct upward trends in the curvatures are observed at lower temperatures. In such a case, the following Vogel-Tamman-Fulcher (VTF) equation is frequently applied [4],

$$
\eta(T)=A_{\eta} \sqrt{T} \exp \left(\frac{B_{\eta}}{T-T_{0 \eta}}\right)
$$

where $A_{\eta}, B_{\eta}$ and $T_{0 \eta}$ are constants to be determined empirically. $T_{0 \eta}$ is called "the ideal glass transition temperature”. The viscosities of the MTFSA melts were fitted very well $\left(R^{2}>0.999\right)$ to the VTF equation with the fitting parameters shown in Table 2.

Among the single salts, the viscosity of Li100 (the abbreviation of the LiTFSA single salt) is extremely high, the viscosity of the salts with the other cations becoming lower with increasing their radii. The viscosities of binary mixtures are somewhere between those of the constituent single salts.

The viscosity of Li07-Cs93 is the lowest in the eutectic LiTFSA-MTFSA ( $M=N a, K, R b$, 
Cs) due to the low concentration of LiTFSA and high concentration of CsTFSA. On the other hand, the viscosity of Li67-Na33 is the highest in the eutectic LiTFSA-MTFSA due to high concentration of LiTFSA. The same tendency is also observed for the eutectic NaTFSA-MTFSA (M = K, Rb, Cs) melts.

3.2 Ionic conductivities of MTFSA single salts and binary eutectic mixtures

Figure 2 shows Arrhenius plots of ionic conductivities for (a) single salts, (b) eutectic LiTFSA-MTFSA ( $\mathrm{M}=\mathrm{Na}, \mathrm{K}, \mathrm{Rb}, \mathrm{Cs})$ and (c) eutectic NaTFSA-MTFSA $(\mathrm{M}=\mathrm{K}, \mathrm{Rb}, \mathrm{Cs})$. Slightly downward curvatures are observed at lower temperatures. Similarly to the case of viscosity, such a temperature dependence is described by the following VTF equation [5];

$$
\sigma(T)=\frac{A_{\sigma}}{\sqrt{T}} \exp \left(-\frac{B_{\sigma}}{T-T_{0 \sigma}}\right)
$$

where $A_{\eta}, B_{\eta}$ and $T_{0 \sigma}$ are constants to be determined empirically. $T_{0 \sigma}$ is called "the ideal glass transition temperature”. The ionic conductivities of most MTFSA melts were fitted quite well $\left(R^{2}>\right.$ 0.999) to this VTF equation by the fitting parameters shown in Table 3. Those of some melts could not be fitted simply due to the shortage of data points.

The ionic conductivity of Li07-Cs93 is the highest in the eutectic LiTFSA-MTFSA $(\mathrm{M}=$ 
$\mathrm{Na}, \mathrm{K}, \mathrm{Rb}, \mathrm{Cs}$ ) melts due to low concentration of LiTFSA and high concentration of CsTFSA. On the other hand, the ionic conductivity of Li67-Na33 is highest in the eutectic LiTFSA-MTFSA melts due to the high concentration of LiTFSA. The same tendency is also observed for the eutectic NaTFSA-MTFSA ( $\mathrm{M}=\mathrm{K}, \mathrm{Rb}, \mathrm{Cs})$ melts. If the comparison is made just above the melting temperatures, the ionic conductivities of these binary eutectic melts are not so high compared to those of room temperature ionic liquids. However, they are considered to be reasonably high for the application of battery electrolytes taking account that these melts contain highly concentrated LiTFSA or NaTFSA at working temperatures from the beginning. In order to apply RTILs for electrolytes of lithium batteries it is necessary to add lithium salts such as LiTFSA, $\mathrm{LiBF}_{4}$ and $\mathrm{LiPF}_{6}$ which significantly increases the viscosities of RTILs. In fact, the ionic conductivity of neat EMImTFSA is $8.8 \mathrm{mS} \mathrm{cm}^{-1}$ at $298 \mathrm{~K}$, but it decreases to $5.1 \mathrm{mS} \mathrm{cm}^{-1}$ by the addition of $0.3 \mathrm{~mol} \mathrm{~kg}^{-1}$ of LiTFSA [6]. On the other hand, LiTFSA in Li43-K57 is highly concentrated and have ionic conductivity equal to EMImTFSA. Thus these molten salts are highly possible to be used directly as the electrolytes for lithium and sodium batteries.

3.4 Relationship between molar conductivity and viscosity

The relation between ionic conductivity and molar conductivity is given by the following equation, 


$$
\lambda=\sigma \frac{M}{d}
$$

where $\lambda$ is molar conductivity, $d$ is density and $M$ is molecular weight or average molecular weight of the melt.

Figure 3 shows the temperature dependence of the densities for (a) single MTFSA salts and (b) binary eutectic mixtures. For all MTFSA salts, densities linearly decrease with the temperature elevation to be expressed by the following equation;

$$
d(T)=A-B T
$$

where $A$ and $B$ are constants. The fitting parameters are given in Table 4. For single salts, densities increase with the increase of molecular weight (from Li to Cs) whose effect exceeds the decrease of density with increase of molecular volume (from Li to Cs). In the case of binary mixtures, densities fall in between those of constituent single salts.

Figure 4 shows the plots of the logarithmic molar conductivity against the logarithmic reciprocal viscosity of (a) single salts, (b) the eutectic LiTFSA-MTFSA ( $M=\mathrm{Na}, \mathrm{K}, \mathrm{Rb}, \mathrm{Cs})$ melts and (c) the eutectic NaTFSA-MTFSA (M = K, Rb, Cs) melts. If the viscosity and conductivity of the electrolyte obeys Walden's rule, the product of molar conductivity and viscosity is constant [7]; 


$$
\lambda \eta=\text { const }
$$

This equation is interpreted as that ionic conductivity of the liquid is governed by their viscosity. A dashed line in Fig. 4 corresponds to $\lambda \eta=1$. Although all the plots of MTFSA melts are on straight lines, their gradients are slightly different from unity. This tendency is called "decoupling” in behavior of ionic conductivity from that of viscosity $[8,9]$. Thus, in the cases of MTFSA melts and their mixtures, the relationship between molar conductivity and viscosity should be described by the fractional Walden's rule presented by the following equation [10];

$$
\lambda \eta^{\alpha}=\text { const. }
$$

where $\alpha$ is a positive constant smaller than one. Table 5 shows $\alpha$ for each system. Such small $\alpha$ of less than one is observed for molten salts in which small singly charged ions exist [11]. This is explained by that alkali metal cations which are much smaller than TFSA anion can move easily among TFSA anions. In the case of single MTFSA melts, the constants fall in the range of 0.84 to 0.90 and they tend to increase with increasing the radius of alkali metal cations. There is a tendency that the larger the difference of radius between cation and anion, the greater the degree of decoupling. In the case of binary MTFSA melts, $\alpha$ is smaller than those of single melts. This suggests that the decoupling is enhanced by mixing two different cations. For some of binary MTFSA salts such as Li07-Cs93, the Walden plots do not fall in the middle of those for the 
constituent single salts but are located above them. This is attributed to the fact that ionic conductivity of Li07-Cs93 is very close to that of Cs100 (see Fig. 2(a) and (b)) although the viscosity of eutectic Li07-Cs93 are higher than that of Cs100 (see Fig. 1(a) and (b)). Such an effect of mixing is favorable for the improvement of the ionic conductivity of electrolytes by reducing the influence of viscosity.

3.5 Electrochemical properties of the binary eutectic melts

Figure 5 shows cyclic voltammograms in Li43-K57 melt at $443 \mathrm{~K}$. A pair of cathodic and anodic currents is observed at $0 \mathrm{~V}$ vs. $\mathrm{Li}^{\square+} / \mathrm{Li}$ on a nickel electrode. These cathodic and anodic currents are interpreted as the deposition of lithium metal and its dissolution, respectively. Galvanostatic electrolysis was performed at $-10 \mathrm{~mA} \mathrm{~cm}^{-2}$ on a nickel electrode in order to identify the reaction at the cathode limit. As a result, a dendritic deposit with partial metallic luster was obtained. When the deposit was analyzed by DSC, endothermic peaks were observed only at the melting point of lithium metal, $454 \mathrm{~K}$ as well as the melting points of the eutectic salt, $423 \mathrm{~K}$. Thus, it was confirmed that only lithium metal deposited on the nickel electrode at the cathode limit of Li43-K57. An anodic current is observed at $5.0 \mathrm{~V} \mathrm{vs.} \mathrm{Li}^{+} / \mathrm{Li}$ on a glassy carbon electrode. This anodic current is considered to correspond to the oxidation of TFSA anion, though more studies are required to elucidate the detail of this reaction. The electrochemical window of Li43-K57 melt is determined as $5.0 \mathrm{~V}$ at $443 \mathrm{~K}$, when the limiting potentials are defined as the potential at a current 
density of $0.1 \mathrm{~mA} \mathrm{~cm}^{-2}$.

Figure 6 shows cyclic voltammograms in Li25-Rb75 melt at $443 \mathrm{~K}$. The obtained cyclic voltammograms are quite similar to that for Li43-K57. In the same manner as described above, it was concluded that the cathode limit is lithium deposition, and the electrochemical window is $5.0 \mathrm{~V}$ at $443 \mathrm{~K}$.

Figure 7 shows a cyclic voltammogram in Li07-Cs93 melt at $403 \mathrm{~K}$. A voltammetric feature is similar to the cases described above, except the anodic current is observed at $5.2 \mathrm{~V}$ vs. $\mathrm{Li}^{+} / \mathrm{Li}$. This value is a slightly higher than that of the anode limit for Li43-K57 and Li25-Rb75 at $443 \mathrm{~K}$. Thus, the decomposition potential of TFSA anion is considered to have temperature dependence. It was confirmed by DSC measurement that lithium metal deposits on a nickel electrode at the cathode limit at $403 \mathrm{~K}$.

Figure 8 shows cyclic voltammograms in the eutectic Na07-Cs93 melt at $403 \mathrm{~K}$. A pair of cathodic and anodic currents is observed on a nickel electrode at $0 \mathrm{~V}$ vs. $\mathrm{Na}+\square / \mathrm{Na}$, which corresponds to the deposition/dissolution of sodium metal. An anodic current is observed on a glassy carbon electrode at $5.0 \mathrm{~V}$. The electrochemical window is $5.0 \mathrm{~V}$ at $403 \mathrm{~K}$. It is also confirmed that only sodium metal deposits on the nickel electrode at the cathode limit from the result of DSC measurement for the deposit.

In comparison of cyclic voltammograms in Li07-Cs93 and Na07-Cs93, the electrochemical window of Li07-Cs93 is wider than that of Na07-Cs93. Since anodic currents of those systems correspond to the same oxidation reaction of TFSA anion, it is reasonably concluded that the 
potential of sodium deposition/dissolution is higher than that of lithium deposition/dissolution. Thus, the order of deposition potential was determined to be $\mathrm{Na}>\mathrm{Li}>(\mathrm{K}, \mathrm{Rb}, \mathrm{Cs})$.

Figure 9 shows cyclic voltammograms in Li67-Na33 melt at $493 \mathrm{~K}$. In this case, a sodium liquid metal was used as the reference electrode. The cathodic current is observed at $-0.2 \mathrm{~V}$ vs. $\mathrm{Na}^{+} / \mathrm{Na}$. When the potential sweep is reversed to the positive direction, two anodic current peaks are observed, which suggests that the deposit is both of Li and Na metal. In the DSC measurement for the deposit at the cathode limit, endothermic peaks were observed at 360, 369 and $450 \mathrm{~K}$. The peak at $360 \mathrm{~K}$ corresponds to the eutectic melting of Li-Na alloy. The peak at $369 \mathrm{~K}$ corresponds to the melting of $\mathrm{Na}$ metal. The peak at $450 \mathrm{~K}$ possibly corresponds to the melting of eutectic salts and lithium metal because the melting temperatures are close to each other, $459 \mathrm{~K}$ for the eutectic salt, and $454 \mathrm{~K}$, for lithium metal. Thus, the deposition of the lithium metal could occur along with the deposition of the sodium metal. On the other hand, anodic dissolutions of lithium and sodium seem to proceed separately. Among two peaks of oxidation currents, the peak at more negative potential is suggested to correspond to the dissolution of lithium metal and the other peak to that of sodium metal according to the order of deposition potential. The deposition of sodium and lithium occurs simultaneously on the nickel electrode probably due to overpotential for sodium deposition. An anodic current is observed at $4.5 \mathrm{~V}$ vs. $\mathrm{Na}^{+} / \mathrm{Na}$ at a glassy carbon electrode. In conclusion, for the eutectic LiTFSA-NaTFSA melt, the electrochemical window is $4.7 \mathrm{~V}$ at $493 \mathrm{~K}$.

It is revealed that those binary melts have wide electrochemical windows and lithium and sodium metals deposit at the cathode limit. Thus, those melts are expected to use as electrolytes of 
lithium or sodium metal batteries such as lithium secondary battery and sodium-sulfur battery.

\section{Conclusions}

Densities, viscosities, ionic conductivities and electrochemical windows of the binary eutectic MTFSA salts have been studied. The densities are measured in order to calculate the molar conductivities. The viscosities of the melts are higher and the ionic conductivities become lower when the concentration of the salt containing a small cation such as lithium ion is higher. However, the binary eutectic MTFSA melts have higher ionic conductivities at intermediate temperatures than room temperature ionic conductivities of room temperature ionic liquids containing lithium salts even with high concentration of lithium salts or sodium salts. The viscosities and the ionic conductivities are described well by VTF equations. Logarithmic molar conductivity is proportional to logarithmic reciprocal viscosity and obeys a fractional Walden's rule. The binary eutectic MTFSA salts have large electrochemical windows of about $5.0 \mathrm{~V}$ at intermediate temperatures. The reactions at the cathode limit of Li43-K57, Li25-Rb75 and Li07-Cs93 melts are identified to be the lithium metal deposition. In the case of Na07-Cs93 melt, the reaction at the cathode limit is sodium metal deposition. In the case of Li67-Na33 melt, the reaction at the cathode limit is simultaneous deposition of sodium and lithium probably due to overpotential for sodium deposition. It has been found that alkali metal deposition is possible in these melts. The anode limit of the binary eutectic 
melts is considered to be the oxidation of TFSA anion. The binary eutectic MTFSA melts are expected to use as electrolytes of lithium or sodium metal batteries. 


\section{References}

[1] R. Hagiwara, K. Tamaki, K. Kubota, T. Goto, T. Nohira, Journal of Chemical \& Engineering

Data 53 (2008) 355.

[2] K. Kubota, T. Nohira, T. Goto, R. Hagiwara, Journal of Chemical \& Engineering Data 53 (2008) 2144.

[3] A. Watarai, K. Kubota, M. Yamagata, T. Goto, T. Nohira, R. Hagiwara, K. Ui, N. Kumagai, J. Power Sources 183 (2008) 724.

[4] A. J. Easteal, C. A. Angell, J. Chem. Phys. 56 (1972) 4231.

[5] C. A. Angell, J. Phys. Chem. 68, (1964) 1917.

[6] H. Matsumoto, H. Sakaebe, K. Tatsumi, M. Kikuta, E. Ishiko, M. Kono, J. Power Sources 160 (2006) 1308.

[7] P. Walden, Z. Phys. Chem. 55 (1906) 207.

[8] C. A. Angell, W. Xu, M. Yoshizawa, A. Hayashi, J. P. Belieres, in: H. Ohno (Ed.), In Ionic Liquids: The Front and Future of Material Development (in Jpn); High Technology Information:

Tokyo, (2003) 43.

[9] C. A. Angell, Wu Xu, M. Yoshizawa, A. Hayashi, J.-P.Belieres, P. Lucas, M. Videa, in: H. Ohno (Ed.), Electrochemical Aspects of Ionic Liquids, Wiley Interscience, (2005) Ch. 2

[10] W. Xu, C. A. Angell, Science 302 (2003) 422.

[11] M. Videa, C. A. Angell, J. Phys. Chem. B 103 (1999) 4185. 


\section{List of tables}

Table 1 . The eutectic temperatures and compositions of binary systems.

Table 2. VTF parameters for viscosities of MTFSA melts.

Table 3. VTF parameters for ionic conductivities of MTFSA melts.

Table 4. The fitting parameters of the densities.

Table 5. The constants of fractional Walden's rule of MTFSA melts. 


\section{List of figures}

Figure 1. Arrhenius plots of viscosities for (a) single MTFSA salts, (b) eutectic LiTFSA-MTFSA ( $\mathrm{M}=\mathrm{Na}, \mathrm{K}, \mathrm{Rb}, \mathrm{Cs})$ melts, and (c) eutectic NaTFSA-MTFSA (M = K, Rb, Cs) melts.

Figure 2. Arrhenius plots of ionic conductivities for (a) single MTFSA salts, (b) eutectic LiTFSA-MTFSA (M = Na, K, Rb, Cs) melts, and (c) eutectic NaTFSA-MTFSA ( $\mathrm{M}=\mathrm{K}, \mathrm{Rb}, \mathrm{Cs})$ melts.

Figure 3. Temperature dependence of densities for (a) single MTFSA salts and (b) binary eutectic MTFSA melts.

Figure 4. Plots of logarithmic molar conductivity against the logarithmic reciprocal viscosity for (a) single MTFSA salts, (b) eutectic LiTFSA-MTFSA (M = Na, K, Rb, Cs) melts, and (c) eutectic NaTFSA-MTFSA $(\mathrm{M}=\mathrm{K}, \mathrm{Rb}, \mathrm{Cs})$ melts.

Figure 5. A combined cyclic voltammogram at a Ni electrode (negative potential region, -0.32 - 3.0 V) and a glassy carbon electrode (positive potential region, 3.8 - 5.2 V) in eutectic Li43-K57 melt at $443 \mathrm{~K}$ (Scan rate: $10 \mathrm{~m} \mathrm{~V} \mathrm{~s}^{-1}$ ).

Figure 6. A combined cyclic voltammogram at a Ni electrode (negative potential region, $-0.26-3.0$ V) and a glassy carbon electrode (positive potential region, 3.2 - 5.2 V) in eutectic Li25-Rb75 melt at $443 \mathrm{~K}$ (Scan rate: $10 \mathrm{~m} \mathrm{~V} \mathrm{~s}^{-1}$ ).

Figure 7. A combined cyclic voltammogram at a Ni electrode (negative potential region, $-0.20-2.2$ V) and a glassy carbon electrode (positive potential region, 3.2 - 5.3 V) in eutectic Li07-Cs93 at 403 $\mathrm{K}$ (Scan rate: $10 \mathrm{mV} \mathrm{s}^{-1}$ ). 
Figure 8. A combined cyclic voltammogram at a Ni electrode (negative potential region, -0.3 - 2.1 V) and a glassy carbon electrode (positive potential region, $3.3-5.2 \mathrm{~V}$ ) in eutectic Na07-Cs93 at $403 \mathrm{~K}$ (Scan rate: $10 \mathrm{mV} \mathrm{s}^{-1}$ ).

Figure 9. A combined cyclic voltammogram at a Mo electrode (negative potential region, -1.0 - 2.0 V) and a glassy carbon electrode (positive potential region, 3.0 - 4.8 V) in eutectic Li67-Na33 melt at $493 \mathrm{~K}$ (Scan rate: $10 \mathrm{~m} \mathrm{~V} \mathrm{~s}^{-1}$ ). 
. The eutectic temperatures and compositions of binary systems.

\begin{tabular}{cccc}
\hline System & $x_{\text {eu }}$ & System & $T_{\text {eu }} / \mathrm{K}$ \\
\hline LiTFSA-NaTFSA & $x_{\text {LiTFSA }}=0.67$ & Li67-Na33 & 459 \\
LiTFSA-KTFSA & $x_{\text {LiTFSA }}=0.43$ & Li43-K57 & 429 \\
LiTFSA-RbTFSA & $x_{\text {LiTFSA }}=0.25$ & Li25-Rb75 & 421 \\
& $x_{\text {LiTFSA }}=0.60$ & Li60-Rb40 & 426 \\
LiTFSA-CsTFSA & $x_{\text {LiTFSA }}=0.07$ & Li07-Cs93 & 391 \\
& $x_{\text {LiTFSA }}=0.70$ & Li70-Cs30 & 434 \\
NaTFSA-KTFSA & $x_{\text {NaTFSA }}=0.25$ & Na25-K75 & 456 \\
NaTFSA-RbTFSA & $x_{\text {NaTFSA }}=0.25$ & Na25-Rb75 & 431 \\
NaTFSA-CsTFSA & $x_{\text {NaTFSA }}=0.07$ & Na07-Cs93 & 392 \\
\hline
\end{tabular}


Table 2. VTF parameters for viscosities of MTFSA melts.

\begin{tabular}{cccc}
\hline System & $10^{3} \times A_{\eta} / \mathrm{cP} \mathrm{K}^{-1 / 2}$ & $B_{\eta} / \mathrm{K}$ & $T_{0 \eta} / \mathrm{K}$ \\
\hline Li100 & 66.4 & 569 & 404 \\
Na100 & 1.37 & 2260 & 173 \\
K100 & 4.08 & 1414 & 215 \\
Rb100 & 10.5 & 949 & 252 \\
Cs100 & 13.8 & 850 & 250 \\
Li67-Na33 & 0.875 & 2330 & 224 \\
Li43-K57 & 6.61 & 1280 & 265 \\
Li25-Rb75 & 0.749 & 2204 & 217 \\
Li07-Cs93 & 4.95 & 1260 & 220 \\
Na25-K75 & 6.68 & 1150 & 253 \\
Na25-Rb75 & 5.96 & 1100 & 259 \\
Na07-Cs93 & 4.34 & 1310 & \\
\hline & & & 216 \\
\hline
\end{tabular}


Table 3. VTF parameters for ionic conductivities of MTFSA melts.

\begin{tabular}{cccc}
\hline System & $10^{-4} \times A_{\sigma} / \mathrm{mS} \mathrm{cm}^{-1} \mathrm{~K}^{1 / 2}$ & $B_{\sigma} / \mathrm{K}$ & $T_{0 \sigma} / \mathrm{K}$ \\
\hline Li100 & 0.254 & 567 & 391 \\
Na100 & - & - & - \\
K100 & - & - & - \\
Rb100 & 5.47 & 1290 & 190 \\
Cs100 & 2.72 & 902 & 227 \\
Li67-Na33 & 1.59 & 1159 & 294 \\
Li43-K57 & 2.44 & 1070 & 258 \\
Li25-Rb75 & 1.67 & 784 & 272 \\
Li07-Cs93 & 2.68 & 881 & 236 \\
Na25-K75 & 4.24 & 1160 & 227 \\
Na25-Rb75 & 2.98 & 987 & 240 \\
Na07-Cs93 & 2.51 & 840 & 242 \\
\hline
\end{tabular}


Table 4. The fitting parameters of the densities.

\begin{tabular}{ccc}
\hline System & $A / \mathrm{g} \mathrm{cm}^{-3}$ & $10^{4} \times B / \mathrm{K}^{-1}$ \\
\hline Li100 & 2.27 & 10.0 \\
Na100 & 2.15 & 7.03 \\
K100 & 2.12 & 6.05 \\
Rb100 & 2.38 & 6.84 \\
Cs100 & 2.77 & 10.5 \\
Li67-Na33 & 2.25 & 9.71 \\
Li43-K57 & 2.27 & 9.39 \\
Li25-Rb75 & 2.43 & 9.20 \\
Li07-Cs93 & 2.74 & 11.1 \\
Na25-K75 & 2.28 & 8.93 \\
Na25-Rb75 & 2.45 & 9.19 \\
Na07-Cs93 & 2.75 & 11.2 \\
\hline
\end{tabular}


Table 5. The constants of fractional Walden's rule of MTFSA melts.

\begin{tabular}{cc}
\hline System & $\alpha$ \\
\hline Li100 & 0.845 \\
Na100 & 0.844 \\
K100 & 0.861 \\
Rb100 & 0.908 \\
Cs100 & 0.900 \\
Li67-Na33 & 0.804 \\
Li43-K57 & 0.813 \\
Li25-Rb75 & 0.743 \\
Li07-Cs93 & 0.834 \\
Na25-K75 & 0.833 \\
Na25-Rb75 & 0.789 \\
Na07-Cs93 & 0.821 \\
\hline
\end{tabular}




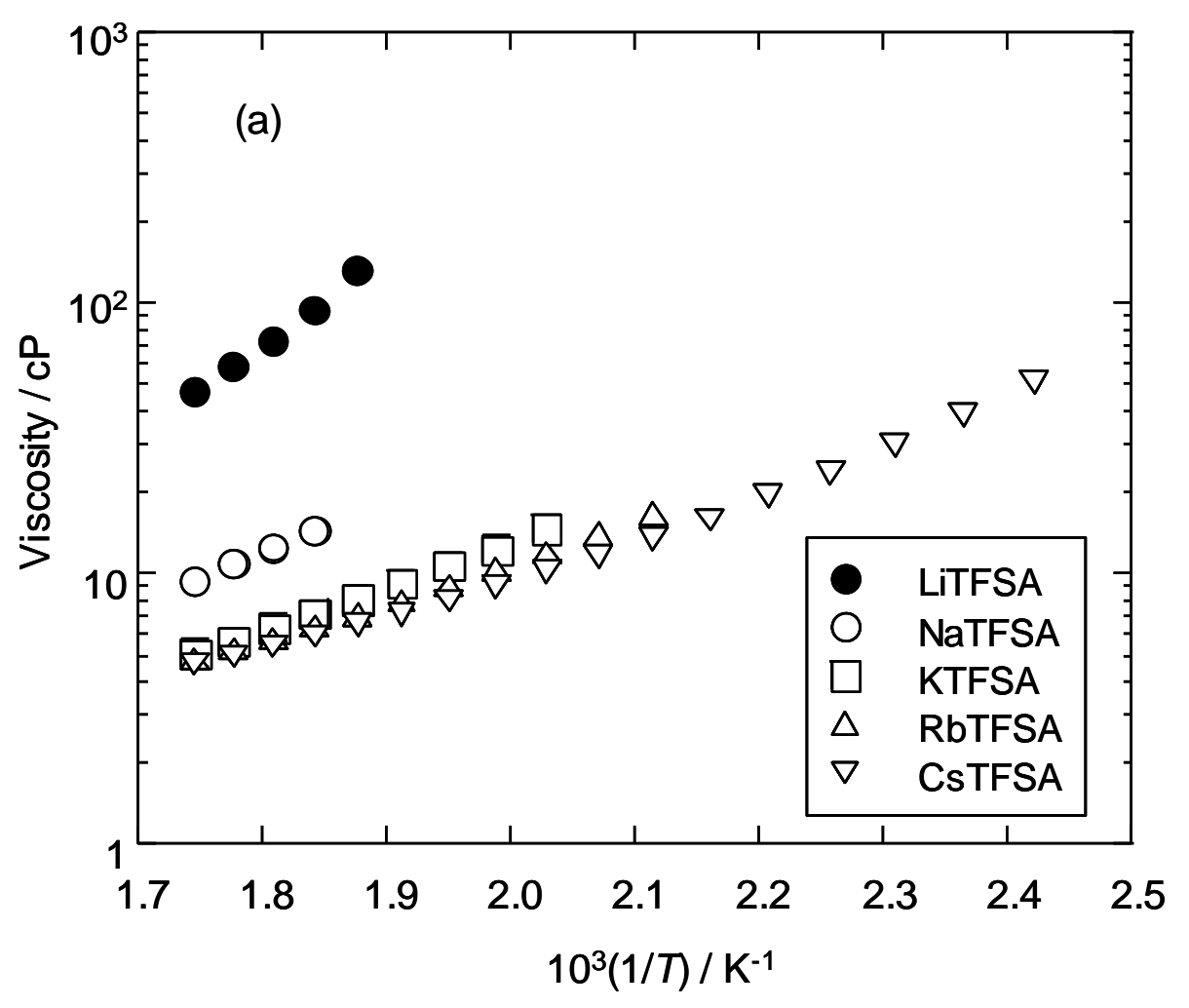

Figure 1(a). 


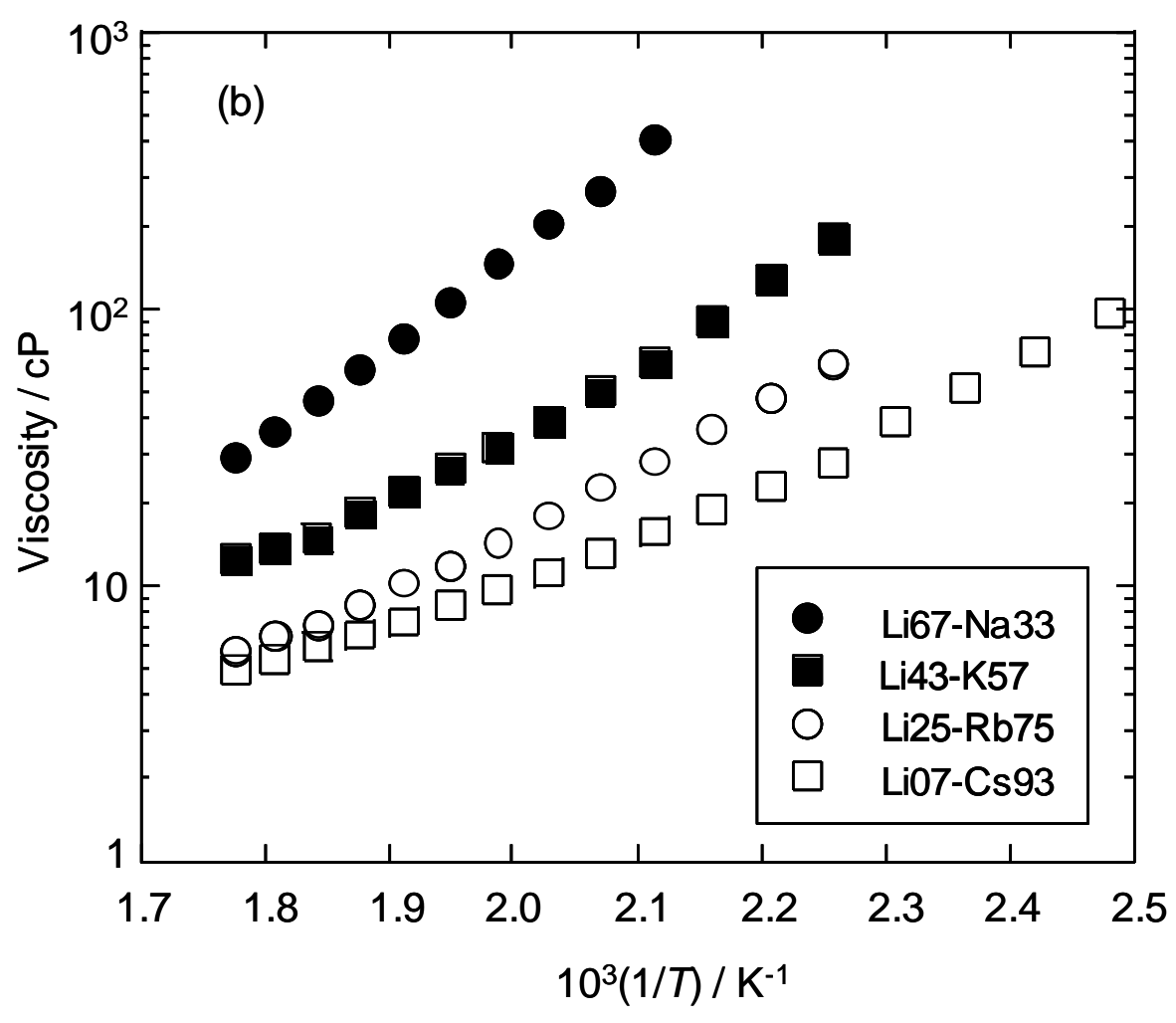

Figure 1(b). 


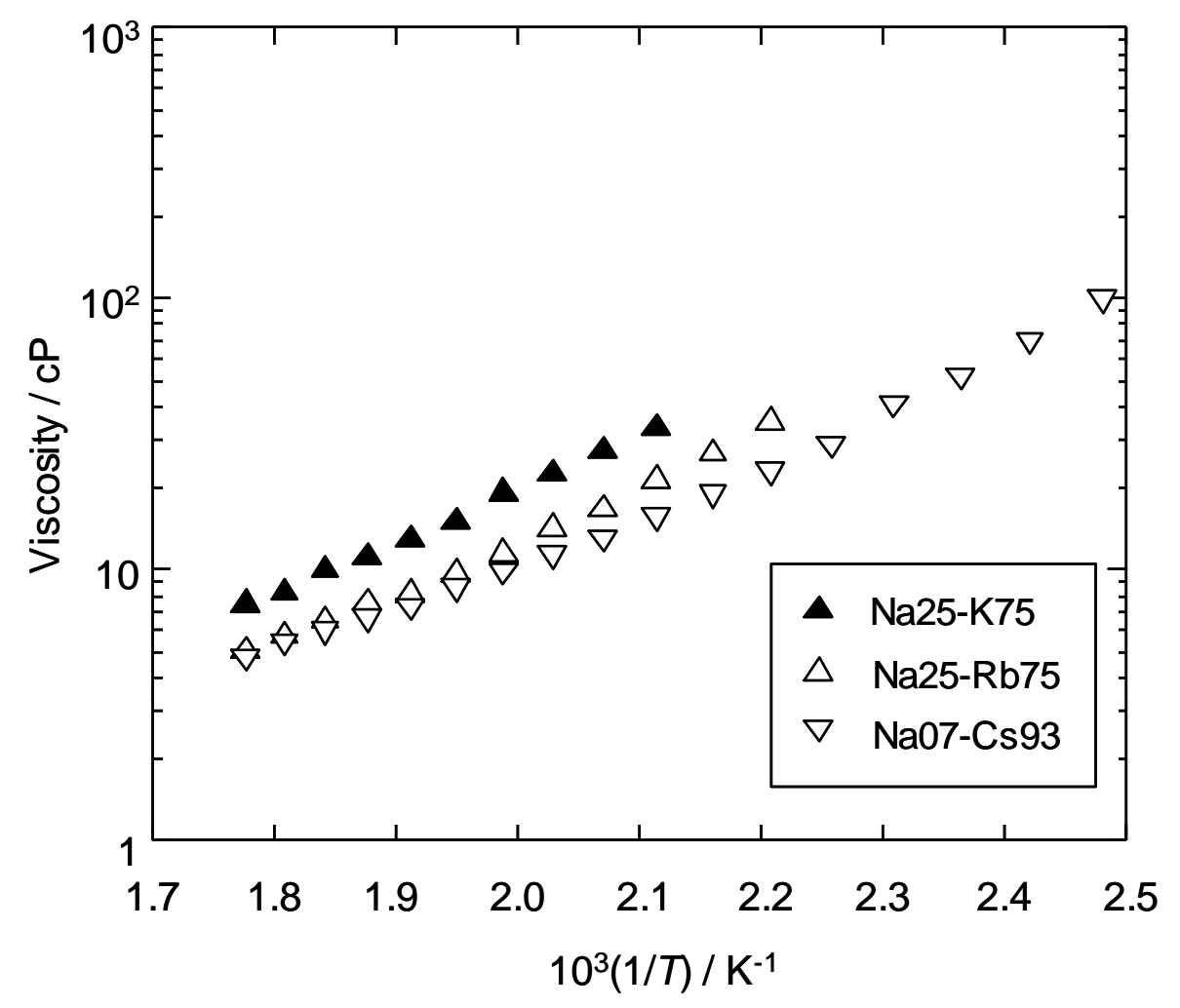

Figure 1(c). 


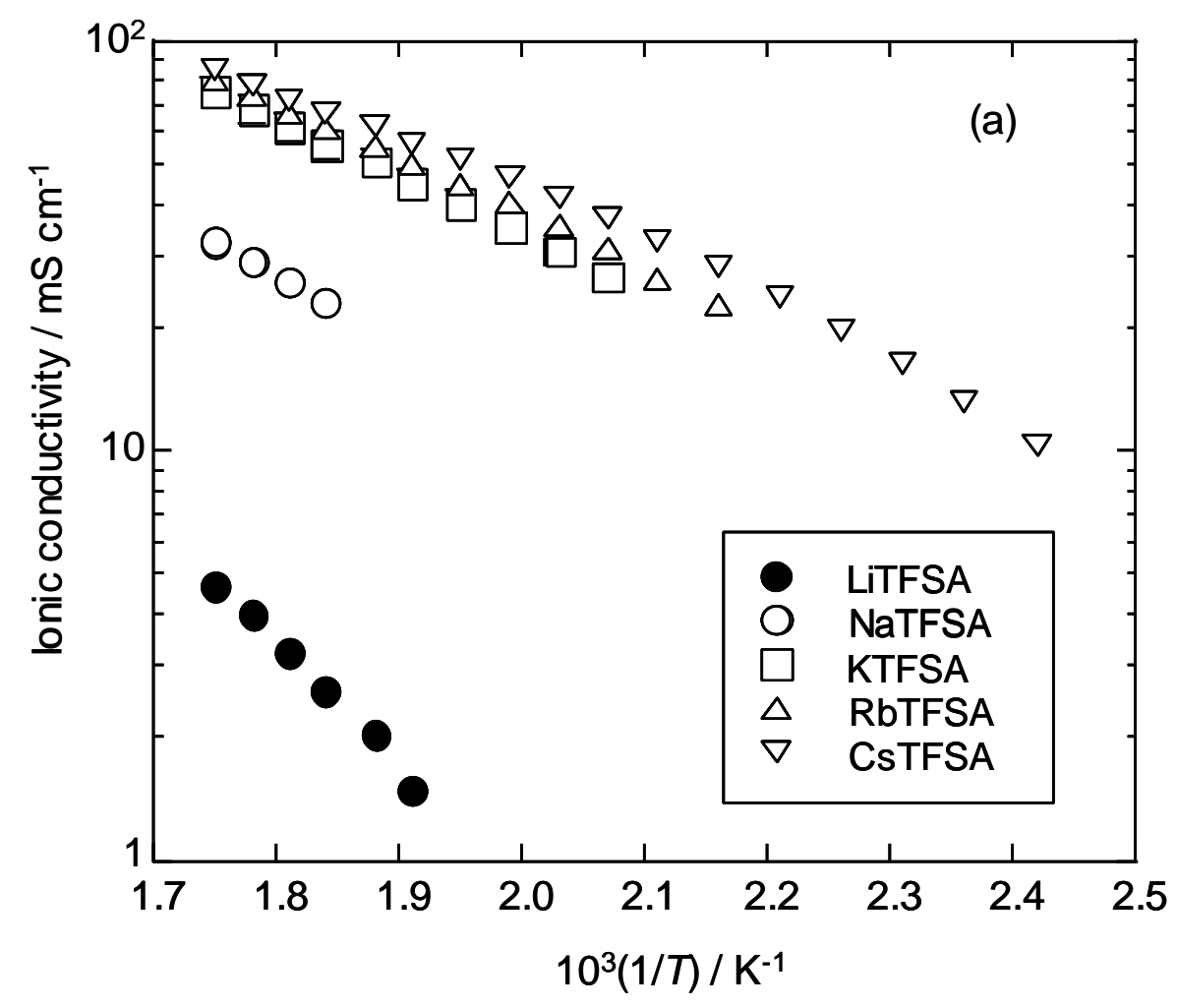

Figure 2(a). 


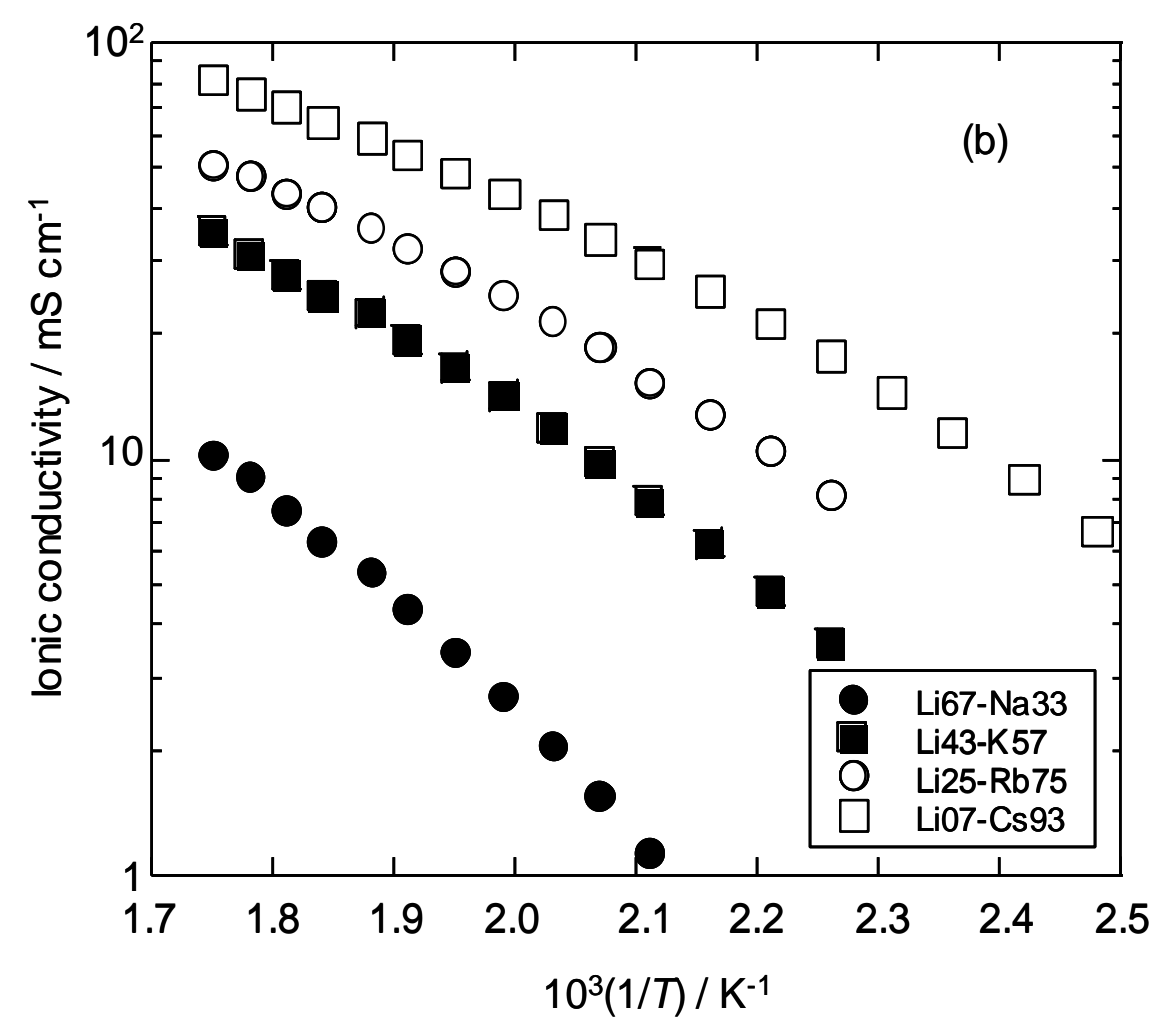

Figure 2(b) 


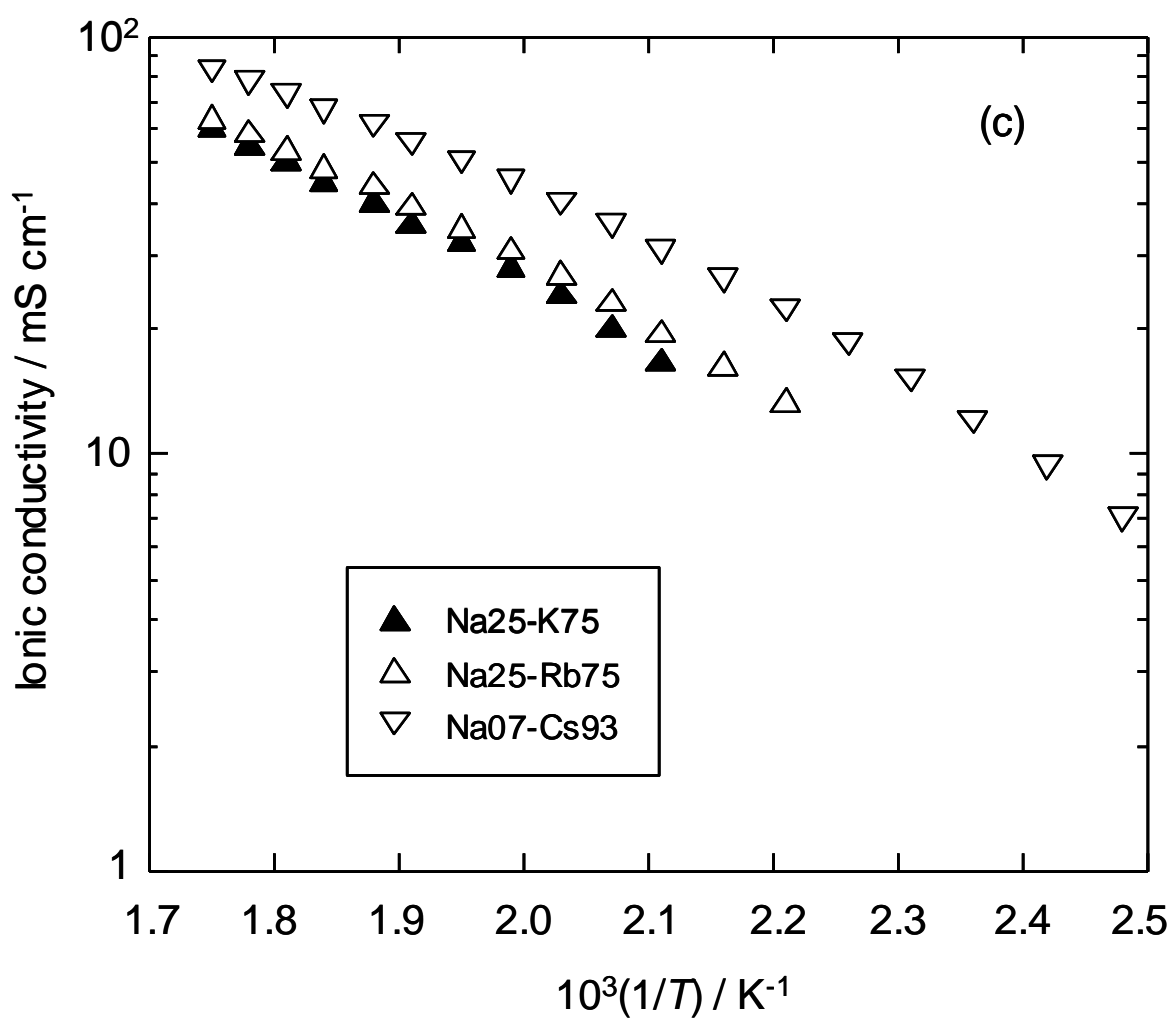

Figure 2(c). 


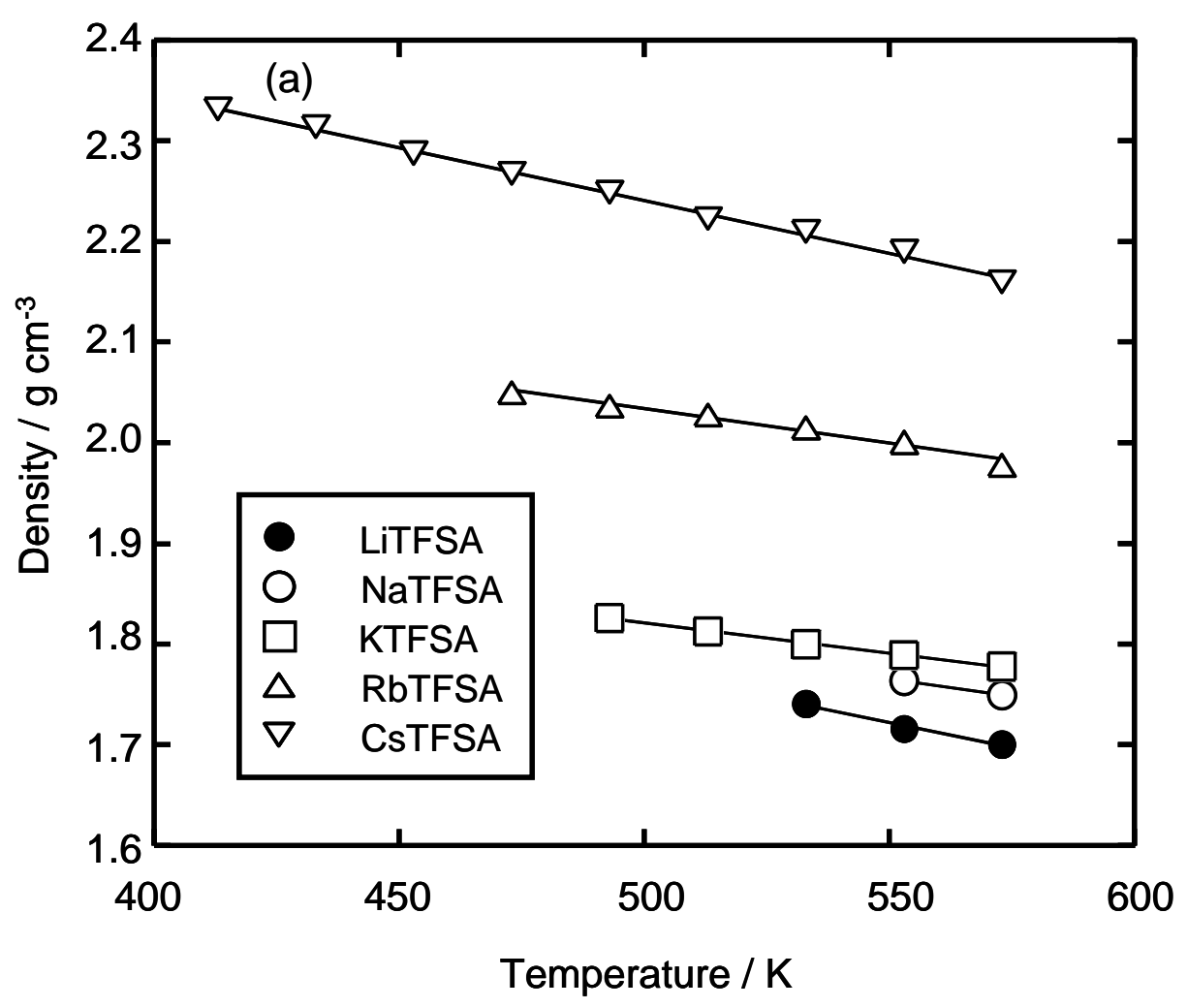

Figure 3(a). 


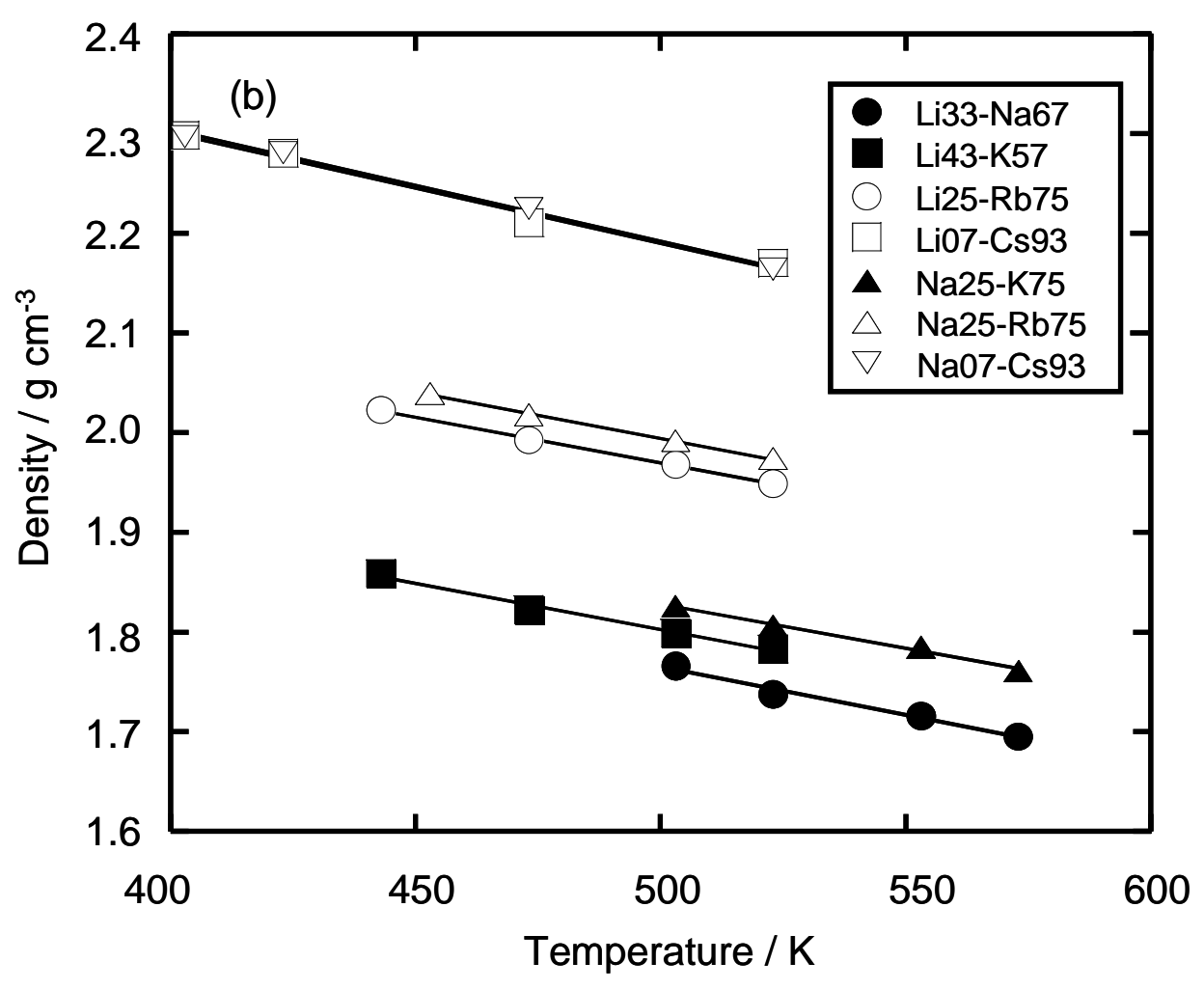

Figure 3(b). 


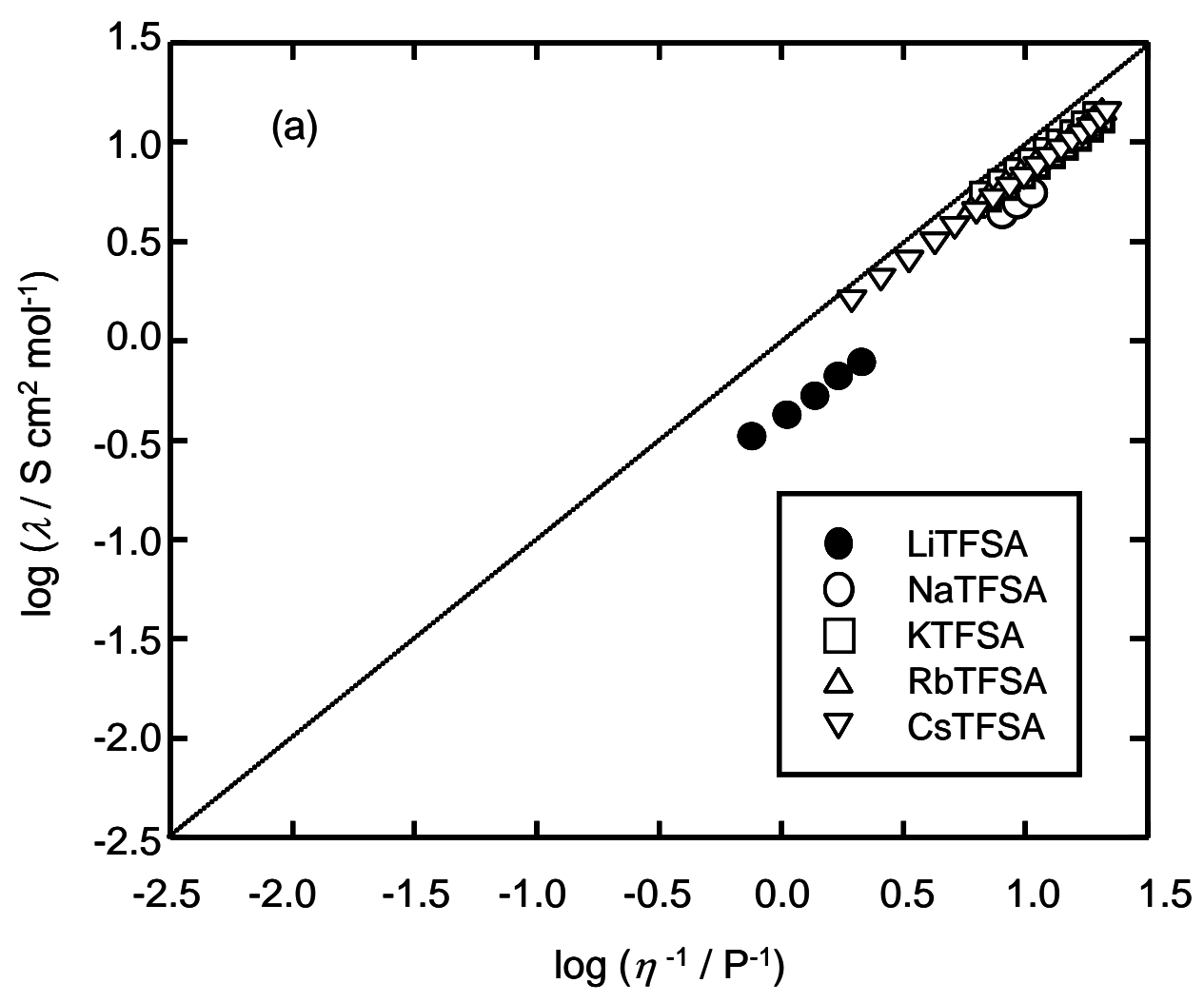

Figure 4(a). 


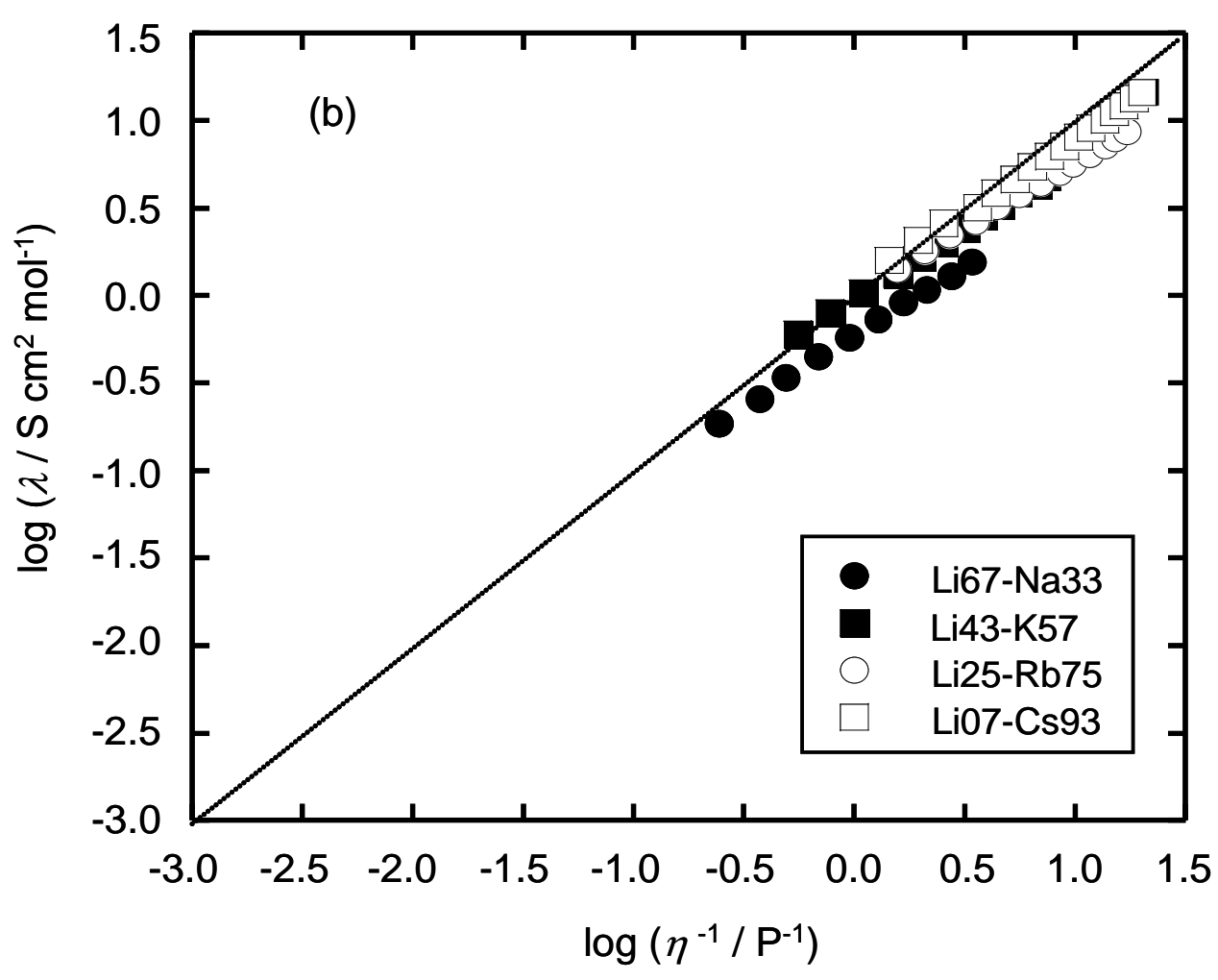

Figure 4(b). 


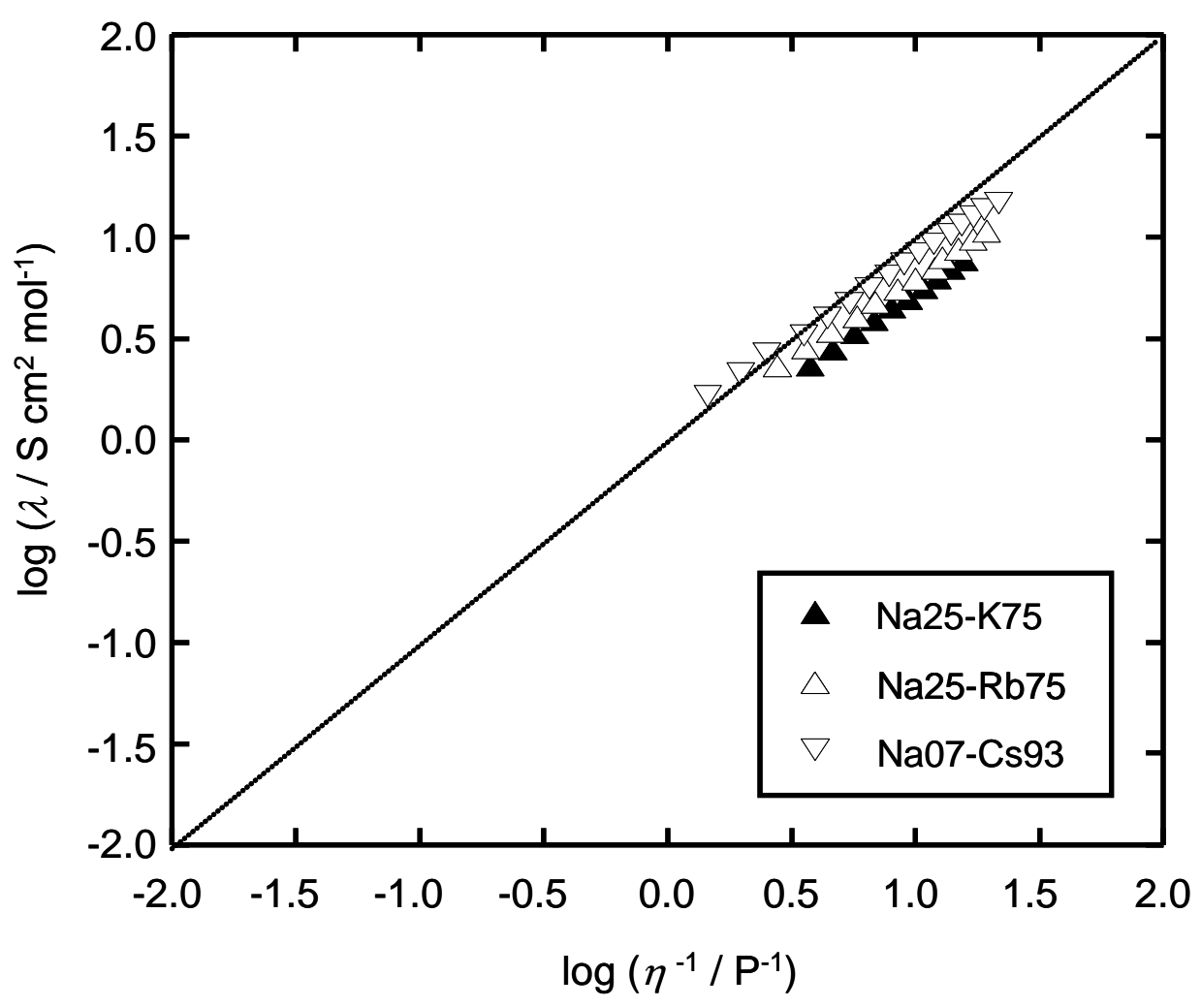

Figure 4(c). 


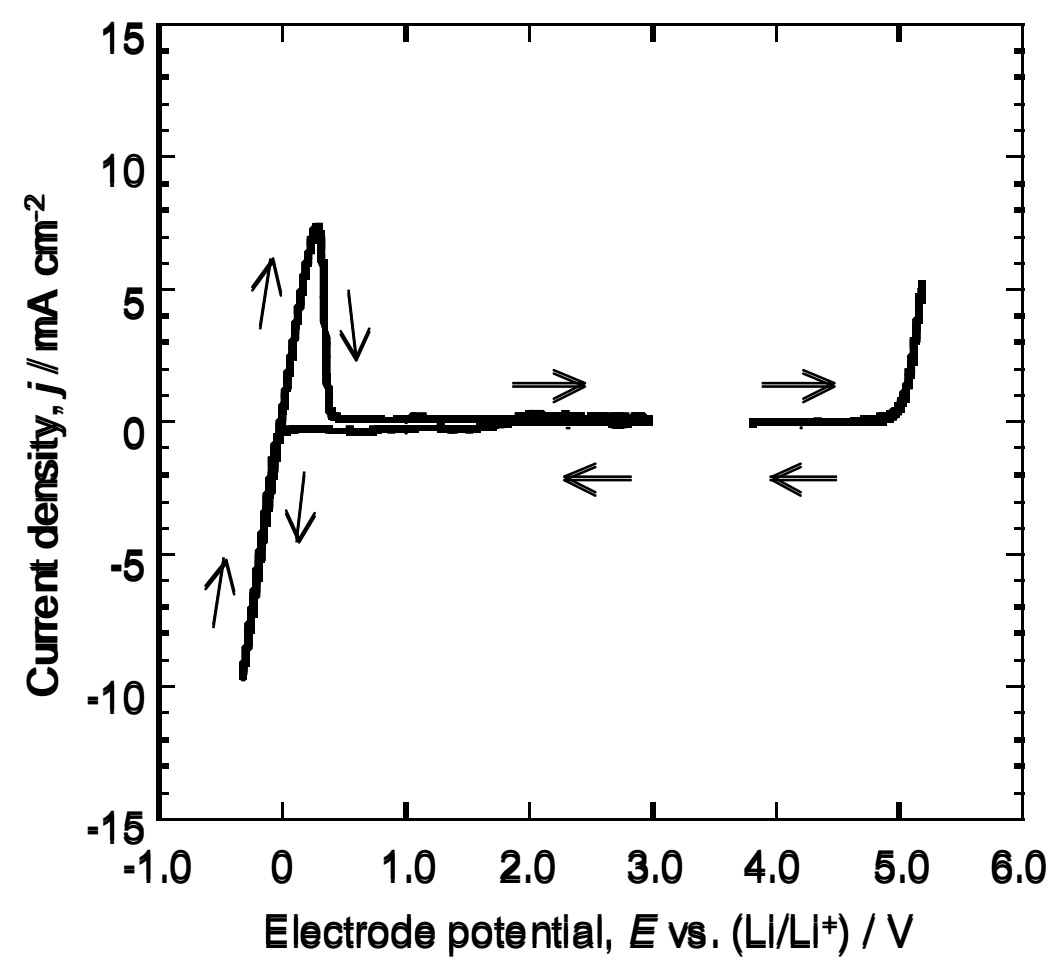

Figure 5. 


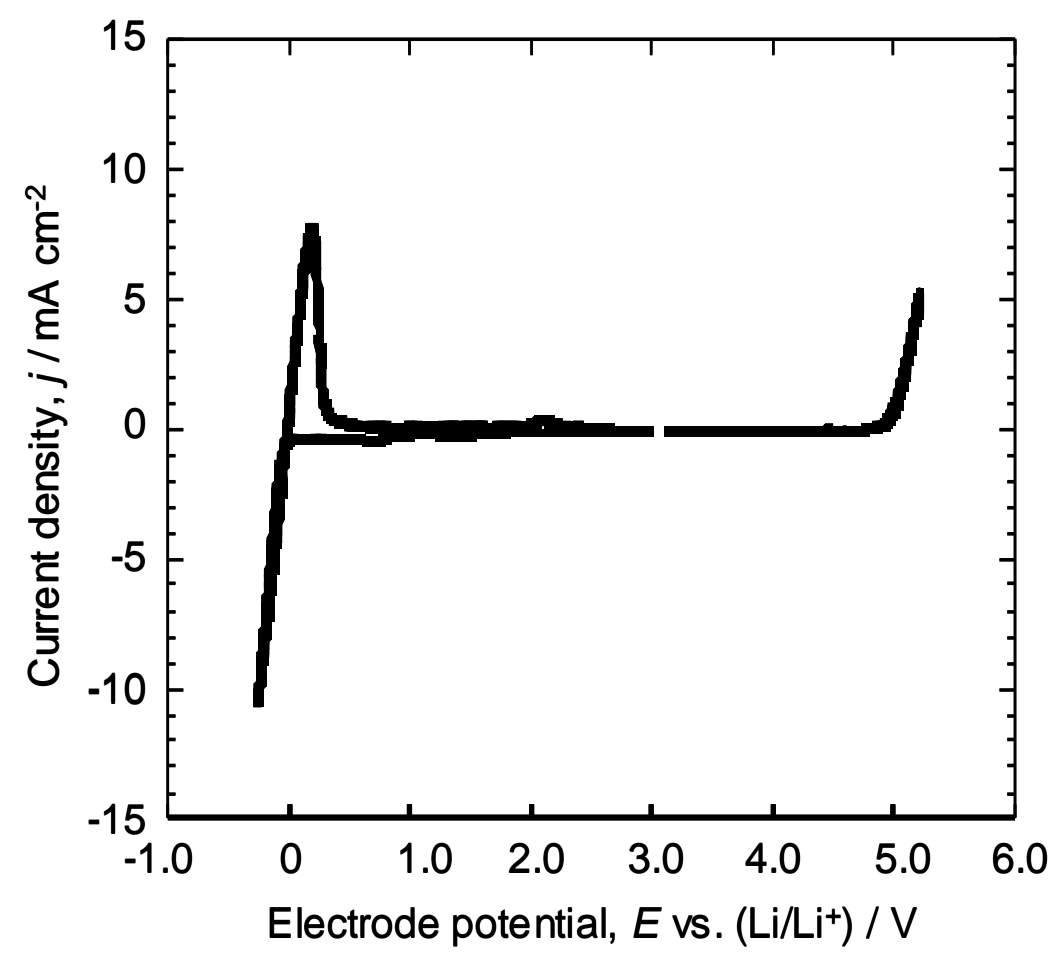

Figure 6. 


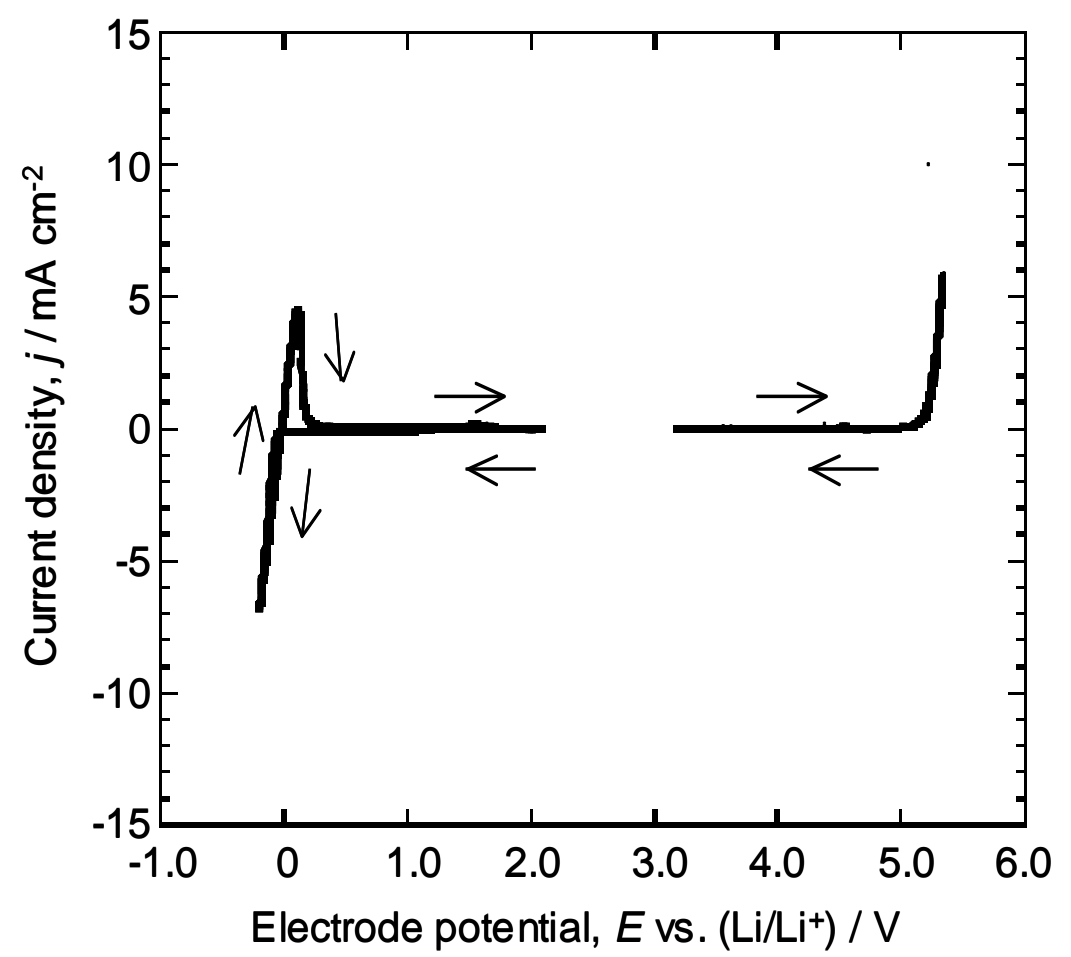

Figure 7. 


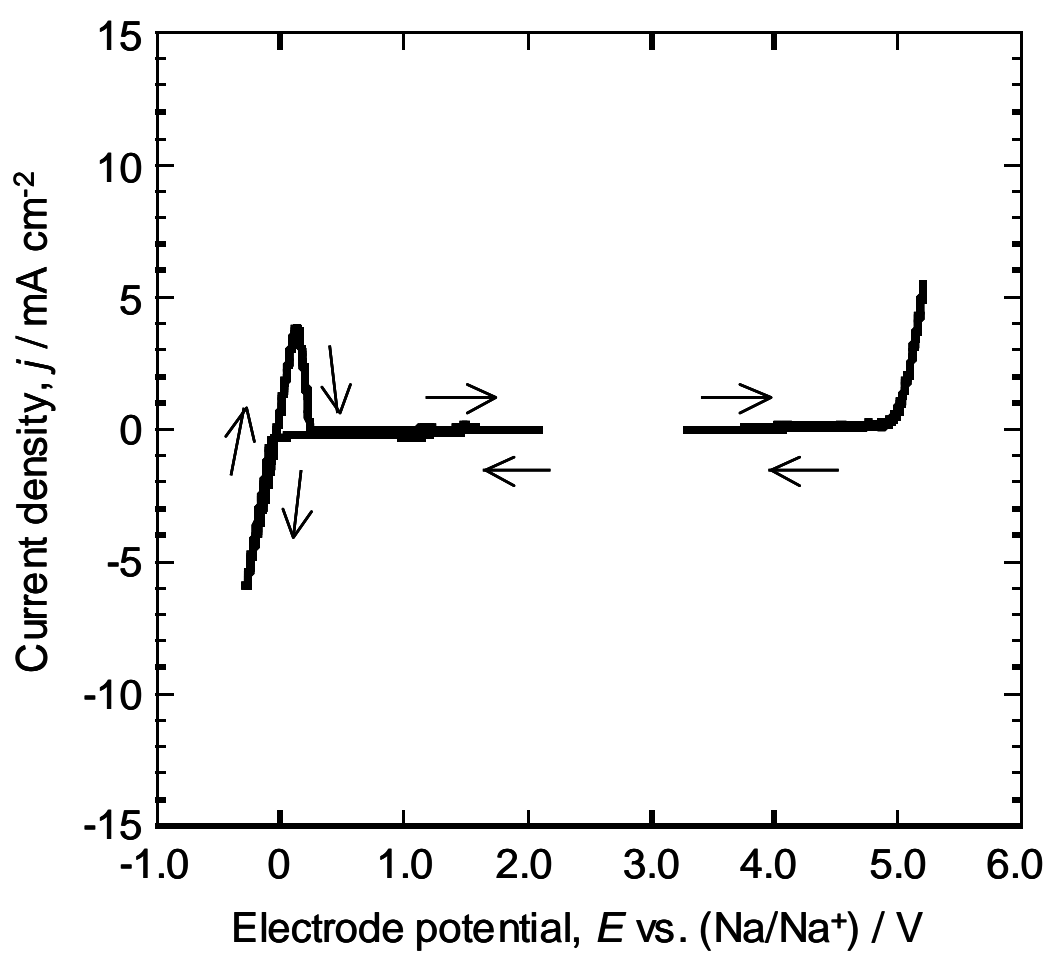

Figure 8. 


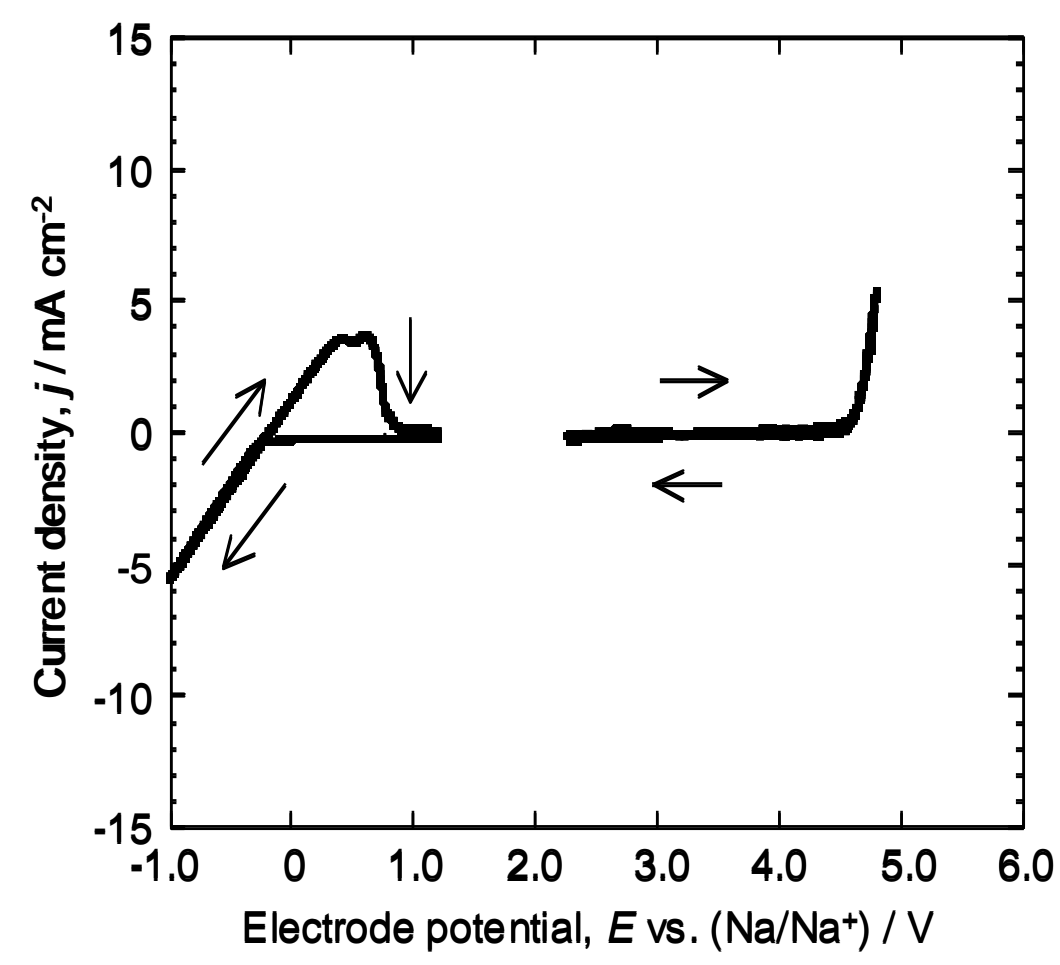

Figure 9. 